\title{
Genetic Background Predicts Poor Prognosis in Frontotemporal Lobar Degeneration
}

\author{
B. Borroni ${ }^{a} \quad$ M. Grassi ${ }^{f} \quad$ S. Archetti ${ }^{b} \quad$ A. Papetti ${ }^{a} \quad$ R. Del Bo ${ }^{g} \quad$ C. Bonvicinic \\ G.P. Comi ${ }^{9}$ M. Gennarellic, d G. Bellellie M. Di Luca ${ }^{\text {h }}$ A. Padovani ${ }^{a}$ \\ ${ }^{a}$ Center for Aging Brain and Dementia, Department of Neurology, University of Brescia, ${ }^{b}$ Department of \\ Laboratories, Brescia Hospital, CIRCCS Fatebenefratelli, d Department of Biomedical Sciences and Biotechnology, \\ University of Brescia, and 'Department of Rehabilitation and Alzheimer's Evaluation Unit, Cremona and Geriatric \\ Research Group, Brescia, ${ }^{f}$ Department of Health Sciences, Section of Medical Statistics and Epidemiology, \\ University of Pavia, Pavia, 9 Dino Ferrari Center, Department of Neurological Sciences, University of Milan, \\ IRCCS 'Foundation Ospedale Maggiore Policlinico, Mangiagalli and Regina Elena', and hCenter of Excellence for \\ Neurodegenerative Disorders, University of Milan, Milan, Italy
}

\section{Key Words}

Frontotemporal lobar degeneration - Frontotemporal dementia $\cdot$ Progranulin $\cdot M A P T$ haplotype $\cdot V E G F$

polymorphisms $\cdot A P O E$

\begin{abstract}
Background: Ruling out predictors of survival in frontotemporal lobar degeneration (FTLD) is a clinical challenge for defining disease outcomes and monitoring therapeutic interventions. Little is known about determinants of survival in FTLD. Objective: The aim of the present study was to identify whether genetic determinants are key, not only as risk factors but as predictors of survival in FTLD. Methods: Ninety-seven FTLD patients were considered in the present study. A clinical evaluation and a standardized assessment were carried out. Each patient underwent blood sampling for genetic testing, and mutations within the progranulin (PGRN) gene, microtubule-associated protein tau (MAPT) haplotype, apolipoprotein $E(A P O E)$ genotype and 4 vascular endothelial growth factor (VEGF) polymorphisms were evaluated. Discrete-time survival models were applied. Results: Mono-
\end{abstract}

\section{KARGER}

Fax +4161306 1234

E-Mail karger@karger.ch

www.karger.com (c) 2011 S. Karger AG, Basel

$1660-2854 / 11 / 0085-0289 \$ 38.00 / 0$

Accessible online at:

www.karger.com/ndd genic FTLD due to $P G R N$ mutations [odds ratio $(\mathrm{OR})=3.62$, $95 \%$ confidence interval $(\mathrm{Cl})=1.12-11.7 ; \mathrm{p}=0.032]$, and $M A P T$ ${ }^{*} \mathrm{H} 2$ haplotype $(\mathrm{OR}=3.23,95 \% \mathrm{Cl}=1.08-9.69 ; \mathrm{p}=0.036)$ were associated with an increased hazard risk of poor outcome. Conversely, APOE genotype, and VEGF polymorphisms were not associated with survival risk in the FTLD sample. Conclusions: Genetic background is not only crucial in disease pathogenesis, but it also modulates disease course. Genetic factors influencing prognosis should be taken into account to include homogeneous groups in future clinical trials and to monitor efficacy of future interventions.

Copyright $\odot 2011$ S. Karger AG, Basel

\section{Introduction}

Frontotemporal lobar degeneration (FTLD) is the second most common form of neurodegenerative dementias in adulthood, after Alzheimer's disease [1]. The improving knowledge of neuropathological hallmarks and disease mechanisms suggests new possible therapeutic targets to be tested in the near future [2]. However, to assess 
the beneficial effect of therapeutic interventions and to include homogeneous patients in clinical trials, a better definition of natural disease course and factors related to higher mortality risk is mandatory [3].

The common experience of clinicians who follow patients with FTLD is the existence of large heterogeneity in the course of the disease not merely explained by clinical phenotypes [4]. A subgroup of these patients shows a benign prognosis over years, others progress to institutionalization with a malignant course. Previous studies demonstrated that FTLD progresses to death faster than Alzheimer's disease [5], but the current literature has still not recognized significantly associated factors at the time of diagnosis to be used in clinical practice as markers of survival risk. Demographic characteristics, age at symptom onset, or family history of dementia do not help in identifying patients with higher risk of mortality [5-11]. More recently, it has been suggested that a positive family history and older age at onset might be predictive of worse prognosis [12]. In the same way, clinical presentation, except for motor neuron disease, is not associated with different patterns of progression over time $[5,6,8$, 13]. Notwithstanding, patients with definite FTLD have a worse prognosis if language deficits are also present [14].

The few available works on survival risk in FTLD have not considered certain variables yet. In this view, as FTLD is recognized as having a stronger genetic background compared to other neurodegenerative dementias, the role of genetic factors should inevitably be analyzed further.

FTLD may present an autosomal dominant pattern of inheritance, and mutations within progranulin (PGRN) $[15,16]$ and microtubele-associated protein tau (MAPT) [17] are recognized as the most common forms of known genes.

However, despite several efforts to identify monogenic causes of FTLD, less interest has been shown in the understanding of the genetic risk factors associated with the disease, and no study has tested the effect of genetic variations of possible candidate genes on disease survival.

It has been demonstrated that MAPT $\mathrm{H} 1 / \mathrm{H} 2$ haplotype influences clinical FTLD presentation [18] and short-term prognosis in FTLD spectrum [11]; on the other hand, apolipoprotein E (APOE) genotype, beyond being the most recognized genetic risk factor for late-onset Alzheimer's disease, might modulate the FTLD clinical picture $[19,20]$. More recently, vascular endothelial growth factor (VEGF) polymorphisms have been associated with increased risk of FTLD [21].

With these caveats in mind, we sought to test whether genetic background, namely PGRN mutations and genet- ic variations within MAPT, APOE and VEGF (-2578C/A, $-1190 \mathrm{G} / \mathrm{A},-1154 \mathrm{G} / \mathrm{A}$, and $-634 \mathrm{G} / \mathrm{C})$, might be associated with higher risk of mortality in FTLD. To this end, we applied discrete-time survival models, and we considered demographic characteristics and disease presentation as possible contributors.

\section{Methods}

\section{Subjects}

This study is part of an ongoing research program aimed at evaluating the core feature of FTLD and predictors of prognosis at the Center for Aging Brain and Neurodegenerative Diseases, University of Brescia, Italy, between 2001 and 2010. Ninety-seven subjects who fulfilled the Neary and McKhann criteria for FTLD $[22,23]$, including behavioral frontotemporal dementia, semantic dementia, and progressive nonfluent aphasia variants, and who met inclusion/exclusion criteria were considered in the present study.

Specifically, inclusion criteria were: (a) full consensus agreement by at least 2 experienced reviewers on FTLD diagnosis; (b) follow-up for at least 2 years after diagnosis, and diagnosis confirmation; (c) blood sampling and genetic test availability. Stringent exclusion criteria were applied as follows: (a) cerebrovascular disorders, previous stroke, hydrocephalus, and intracranial mass documented by MRI; (b) a history of traumatic brain injury or other neurological diseases; (c) significant medical problems (e.g. poorly controlled diabetes or hypertension; cancer within the past 5 years; clinically significant hepatic, renal, cardiac, or pulmonary disorders); (d) major depressive disorder, bipolar disorder, schizophrenia, substance abuse disorder, or mental retardation according to criteria of the DSM-IV; (e) FTLD with motor neuron disease.

\section{Variables}

All subjects underwent a somatic and neurological evaluation, and routine laboratory examinations, a brain structural MRI and/or brain functional study by single photon emission tomography. The diagnostic assessment involved a review of full medical history, a semi-structured neurological examination, and a complete mental status evaluation.

All patients underwent a cognitive, behavioral and functional examination according to a standardized FTLD assessment, as previously published [11].

In the present study, age at onset, clinical features, and genetic variables were considered. Briefly, the age at onset of symptoms was based on a family report of the earliest persistently abnormal clinical feature in the domains of language, social function or personality change, or executive functioning. Patients considered to have a positive family history were those who had a first-degree relative with dementia. In regard to comorbidities, history of hypertension, diabetes mellitus, hypercholesterolemia and cardiomyopathy were assessed in each subject. Hypertension was considered present either if systolic blood pressure was $>140 \mathrm{~mm} \mathrm{Hg}$ and diastolic pressure $>90 \mathrm{~mm} \mathrm{Hg}$ in more than 3 separate measurements, or if the subject was treated with antihypertensive drugs before recruitment. The diagnosis of diabetes mellitus was 
established according to WHO criteria. Hypercholesterolemia was considered present either if cholesterol serum levels were $>220 \mathrm{mg} / \mathrm{dl}$ or if the subject was under treatment with cholesterollowering drugs. The presence of atrial fibrillation, ischemic cardiomyopathy or hypertensive cardiomyopathy was also considered according to common clinical criteria.

Blood sampling was carried out after informed consent for genetic analyses. In each patient, mutations within $P G R N$ gene were analyzed, as well as MAPT haplotype, $A P O E$ genotype and 4 different VEGF polymorphisms (-2578C/A, -1190G/A, -1154G/ $\mathrm{A}$, and $-634 \mathrm{G} / \mathrm{C})$. FTLD patients were screened for MAPT mutations; in the present analysis, $M A P T$ pathogenetic mutations were not considered, because only 1 patient carried monogenic MAPT disease.

All participants were made fully aware of the research goals, and the signature of an informed consent was required from all subjects. The work was conducted in accordance with local clinical research regulations and in conformity with the Declaration of Helsinki.

\section{Genetic Analyses}

Total genomic DNA was prepared from peripheral blood according to standard procedures.

PGRN Sequencing. All the 12 exons plus exon 0 of $P G R N$ and at least 30 base pairs (bp) of their flanking introns were evaluated by polymerase chain reaction (PCR). PCR primers were designed to optimize denaturing high-performance liquid chromatography (dHPLC) conditions, following previously provided primer pairs, as previously published [24]. The dHPLC method was adopted to screen, and samples with an altered dHPLC profile were purified with Microcon centrifugal filter devices (Amicon Bioseparation - Millipore) and sequenced. Sequencing was performed in duplicate from purified PCR on the 310 DNA sequencer ABI Prism (Applera Biosystems, Italy), according to the manufacturer's instructions. Sequences were compared with those available in public databases.

MAPT Haplotype Analysis. MAPT haplotype was evaluated by saitohin gene (STH) amplification using the forward primer $5^{\prime}$ CCA AGT TCA GTT GCC ATC TCC 3' and reverse primer 5' CTC TTG TGC ATG GAC CCT GTA 3'. PCR product consisted of a fragment of $795 \mathrm{bp}$. PCR was performed using $200 \mathrm{ng}$ of genomic DNA in $50 \mu \mathrm{l}$ of reaction mixture consisting of $0.2 \mathrm{mM}$ of each primer, $5 \mathrm{mM}$ of deoxynucleotide triphosphate, $2.5 \mathrm{mM}$ of $\mathrm{MgCl}_{2}, 5 \mathrm{nl}$ of $10 \times$ PCR buffer and $2.5 \mathrm{U}$ of Taq polymerase. After initial denaturation at $95^{\circ} \mathrm{C}$ for $5 \mathrm{~min}$, the reaction mixture was subjected to 35 cycles of 40 -second denaturation at $95^{\circ} \mathrm{C}$, 2-min annealing at $56^{\circ} \mathrm{C}, 1$-min extension at $72^{\circ} \mathrm{C}$, followed by a final 10 -min extension step at $72^{\circ} \mathrm{C}$. Genotyping of the $S T H$ single nucleotide polymorphism was performed by digesting the PCR product with Hinf I restriction enzyme (New England Biolabs). The $S T H^{*} \mathrm{Q}$ allele was characterized by 5 fragments of 261,243 , 194,54 , and $30 \mathrm{bp}$, while the $S T H^{*} \mathrm{R}$ allele was characterized by 2 fragments of $97 \mathrm{bp}$, a fragment of $261 \mathrm{bp}$ and 1 of $243 \mathrm{bp}$.

$A P O E$ Genotyping. Genetic variation at the APOE locus was determined by restriction isotyping using PCR amplification and subsequent digestion with Hha I (Qbiogene). The nucleotide substitutions that result in Arg-Cys interchange at position 112 and 158 alter Hha I cleavage sites: each genotype can be distinguished by unique combinations of Hha I fragment sizes in all homozygotic and heterozygotic combinations.
VEGF Genotyping. Two genomic DNA regions containing portions of the VEGF promoter were amplified by PCR. The amplification protocol was as follows: $5 \mathrm{~min}$ at $94^{\circ} \mathrm{C}$ for the first cycle, denaturation at $94^{\circ} \mathrm{C}$ for $30 \mathrm{~s}$, annealing at $60^{\circ} \mathrm{C}$ for $30 \mathrm{~s}$, extension at $72^{\circ} \mathrm{C}$ for $30 \mathrm{~s}$ for the subsequent 35 cycles, and a final extension at $72^{\circ} \mathrm{C}$ for $5 \mathrm{~min}$. To detect the polymorphism $\mathrm{C}(-2578) \mathrm{A}$, fragments were directly electrophoresed on a $3 \%$ agarose gel because of an 18-nucleotide insertion always associated with the $-2578 \mathrm{~A}$ allele, whereas CC homozygotes do not contain this insertion. $-1190 \mathrm{G} / \mathrm{A}$ and $-1154 \mathrm{G} / \mathrm{A}$ variants were detected through direct sequencing analysis of PCR fragments using BigDyeTerminator protocol on an automated 3100 ABI Prism Genetic Analyzer (Applied Biosystem, Foster City, Calif., USA). The polymorphism G(-634)C (rs2010963) was detected by allelic discrimination through a TaqMan SNP genotyping assay (ID: C_8311614_10) on an ABI Prism 7000 instrument (Applied Biosystem).

\section{Follow-Up Outcomes}

Each patient was followed up over a 9-year period from the time of the study enrolment/diagnosis, and the survival times were recorded in years from the age at onset of symptoms. The binary endpoint was determined as the entry to nursing home or other long-term care facility (institutionalization) and death (outcome $=1$ ), and otherwise (no institutionalization/death, outcome $=0$ ). Endpoints were determined by clinical periodic followup when possible, or by a semi-structured telephone interview.

\section{Statistical Analysis}

Results are given as means \pm standard deviation (SD). All statistical tests were 2 -sided, and p values less than 0.05 were considered statistically significant. FTLD groups were compared by means of one-way ANOVA or $\chi^{2}$ test, as appropriate.

Since the continuous times were replicated in many patients, and the number of time values is less than 20, discrete-time survival analysis models (for an overview, see Singer and Willett [25]) were performed using six time intervals of the follow-up period: $1-2,3-4,5-6,7-8,9-10$, and $>10$ years.

Only time-independent covariates have been considered, thus only covariates whose values remain constant during follow-up. The survival analysis investigated demographic features (age at onset, and gender), clinical variables (diagnosis, family history, history of hypertension, hypercholesterolemia, diabetes, and cardiomyopathy) and genetic background (PGRN mutation and $M A P T$ haplotype, APOE genotype, VEGF polymorphisms). Univariate models (single predictor entered in the multiple models) and one multivariate model (all predictors entered in a single model) were fitted. In the multivariate model, total number of comorbidities (from 0 to 4), and total number of VEGF polymorphisms (from 0 to 4 ) were considered for reducing multicollinearity.

The maximum likelihood estimates of model parameters (= hazard odds ratios, OR), 95\% confidence intervals $(95 \%$ $\mathrm{CI}$ ), and $\mathrm{p}$ values of the $\mathrm{t}$ test (= parameter estimate/standard error) using 'robust' standard error were reported.

Data analysis and discrete-time survival modeling were performed using the SPSS (version 15.0) software (www.spss.com), and Mplus (version 6.0) software (www.mplus.com), respectively. 
Table 1. Demographic and clinical characteristics of included FTLD patients

\begin{tabular}{|c|c|c|c|c|c|}
\hline & $\begin{array}{l}\text { FTLD overall } \\
(\mathrm{n}=97)\end{array}$ & $\begin{array}{l}\text { bvFTD } \\
(\mathrm{n}=80)\end{array}$ & $\begin{array}{l}\mathrm{SD} \\
(\mathrm{n}=8)\end{array}$ & $\begin{array}{l}\text { PNFA } \\
(n=9)\end{array}$ & $\mathrm{p}$ value ${ }^{2}$ \\
\hline Age at onset, years & $63.6 \pm 7.8$ & $63.5 \pm 7.8$ & $68.6 \pm 9.0$ & $60.5 \pm 7.5$ & 0.094 \\
\hline Age at diagnosis, years & $65.6 \pm 7.8$ & $65.6 \pm 7.5$ & $70.3 \pm 9.0$ & $63.1 \pm 8.6$ & 0.146 \\
\hline Female gender, $\%$ & $51.5(50)$ & $48.8(39)$ & $75.0(6)$ & $55.6(5)$ & 0.335 \\
\hline Family history, \% & $42.3(41)$ & $43.8(35)$ & $25.0(2)$ & $44.4(4)$ & 0.587 \\
\hline \multicolumn{6}{|l|}{ Clinical variables } \\
\hline Hypertension, \% & $36.6(34)$ & $37.7(29)$ & $28.6(2)$ & $33.3(3)$ & 0.872 \\
\hline Hypercholesterolemia, \% & $39.4(37)$ & $42.9(33)$ & $25.9(2)$ & $22.2(2)$ & 0.334 \\
\hline Diabetes, $\%$ & $12.9(12)$ & $14.3(11)$ & 0.0 & $11.1(1)$ & 0.612 \\
\hline Cardiomyopathy, \% & $16.0(15)$ & $17.9(14)$ & 0.0 & $11.1(1)$ & 0.424 \\
\hline Comorbidities, $\mathrm{n}$ & $1.05 \pm 0.98$ & $1.13 \pm 0.98$ & $0.50 \pm 0.54$ & $0.77 \pm 1.28$ & 0.218 \\
\hline \multicolumn{6}{|l|}{ Genetic background } \\
\hline PGRN mutations, $\mathrm{n}$ & $7.2(7)$ & $5.0(4)$ & 0.0 & $33.3(3)$ & 0.006 \\
\hline$A P O E^{1} \varepsilon 4, \%$ & $29.0(27)$ & $30.3(23)$ & $37.3(3)$ & $11.1(1)$ & 0.380 \\
\hline$M A P T^{1} \mathrm{H} 2$ haplotype, $\%$ & $40.0(36)$ & $37.3(28)$ & $71.4(5)$ & $37.5(3)$ & 0.210 \\
\hline \multicolumn{6}{|l|}{$V E G F^{1}$} \\
\hline$-2578 \mathrm{C} / \mathrm{A}, \mathrm{AA}, \%$ & $22.6(19)$ & $23.9(17)$ & $14.3(1)$ & $16.7(1)$ & 0.790 \\
\hline$-1190 \mathrm{G} / \mathrm{A}, \mathrm{AA}, \%$ & $25.0(21)$ & $28.2(20)$ & 0.0 & $16.7(1)$ & 0.230 \\
\hline$-1154 \mathrm{G} / \mathrm{A}, \mathrm{AA}, \%$ & $17.9(15)$ & $19.7(14)$ & 0.0 & $16.7(1)$ & 0.428 \\
\hline$-634 \mathrm{G} / \mathrm{C}, \mathrm{CC}, \%$ & $10.0(8)$ & $9.0(6)$ & $14.3(1)$ & $16.7(1)$ & 0.771 \\
\hline VEGF polymorphisms, $\mathrm{n}$ & $0.78 \pm 1.00$ & $0.85 \pm 1.04$ & $0.28 \pm 0.48$ & $0.66 \pm 0.81$ & 0.353 \\
\hline
\end{tabular}

bvFTD = Behavioral variant of frontotemporal dementia; $\mathrm{SD}=$ semantic dementia; PNFA = progressive nonfluent aphasia. Number of subjects are given in parentheses.

${ }^{1}$ Differences in the total are due to missing values: smoking habits $=81$ cases, $A P O E$ and $M A P T=90$ cases, $V E G F$ polymorphisms $=84$ cases available.

${ }^{2} \mathrm{~F}$ test of one-way ANOVA or $\chi^{2}$ test, as appropriate.

\section{Results}

Among 180 FTLD patients, 97 subjects fulfilling inclusion and exclusion criteria and with genetic testing available were considered in the present analysis.

Demographic, clinical and genetic features according to clinical diagnosis are reported in table 1. FTLD patients were homogeneous across clinical diagnoses. The average time delay between age at diagnosis and age at onset of symptoms was equal to 2 years ( $\mathrm{SD}=1.7$ years). Seven out of 97 patients carried PGRN mutations (7.2\%), namely T272SfsX10 $(\mathrm{n}=6)$ and Q341X $(\mathrm{n}=1)$. Forty percent of patients carried at least one $M A P T^{*} \mathrm{H} 2$ allele $(\mathrm{H} 1 /$ $\mathrm{H} 2$ or $\mathrm{H} 2 / \mathrm{H} 2$ ), and $29 \%$ the APOE $\varepsilon 4$ allele. Thirty-two out of 97 FTLD patients had been institutionalized or died throughout the follow-up observation. In the overall group, the average survival time from the onset of symptoms was 6.2 years ( $\mathrm{SD}=2.9$ years), and the failure rate was about 5 events per 100 person-years at risk.
The univariate (crude) and multivariate (adjusted for) hazard OR estimates from discrete-time survival models are reported in table 2 . There was no significant evidence to suggest that gender, positive family history of dementia, and comorbidities, i.e. history of hypertension, hypercholesterolemia, diabetes, and cardiomyopathy, significantly correlated with the rate of survival. Clinical diagnoses and age at onset of symptoms predicted the survival rate in FTLD only when either the crude OR or multivariate model were considered, respectively.

Conversely, as shown in table 2, genetic background significantly predicted the survival rate in FTLD patients in both the univariate and multivariate models. In particular, monogenic cases due to $P G R N$ mutations $(\mathrm{OR}=$ $5.11,95 \% \mathrm{CI}=1.83-14.2, \mathrm{p}=0.002$ for univariate model, and $\mathrm{OR}=3.62,95 \% \mathrm{CI}=1.12-11.7, \mathrm{p}=0.032$ for multivariate model), and patients carrying the $M A P T{ }^{*} \mathrm{H} 2$ haplotype $(\mathrm{OR}=2.67,95 \% \mathrm{CI}=1.10-6.46, \mathrm{p}=0.029$ for 
Table 2. Hazard OR estimates of prognostic factors according to univariate and multivariate discrete-time survival models

\begin{tabular}{|c|c|c|c|c|}
\hline \multirow[t]{2}{*}{ Prognostic factor } & \multicolumn{2}{|l|}{ Univariate model } & \multicolumn{2}{|c|}{ Multivariate model } \\
\hline & OR $(95 \% \mathrm{CI})$ & $\mathrm{p}$ value & OR (95\% CI) & $\mathrm{p}$ value \\
\hline Age at onset (years) & $1.04(0.99-1.09)$ & 0.104 & $1.09(1.03-1.16)$ & 0.005 \\
\hline Gender $(1$ = female $)$ & $0.76(0.34-1.68)$ & 0.495 & $0.80(0.36-1.78)$ & 0.577 \\
\hline \multicolumn{5}{|l|}{ Clinical variables } \\
\hline Diagnosis (1 = bvFTD) & $0.45(0.21-0.98)$ & 0.045 & $0.85(0.32-2.23)$ & 0.739 \\
\hline Family history ( 1 = yes $)$ & $1.03(0.45-2.34)$ & 0.952 & $1.57(0.64-3.84)$ & 0.325 \\
\hline Hypertension $(1=$ yes $)$ & $0.54(0.19-1.54)$ & 0.252 & - & \\
\hline Hypercholesterolemia ( 1 = yes) & $0.50(0.20-1.25)$ & 0.137 & - & \\
\hline Diabetes $(1=$ yes $)$ & $1.23(0.39-3.87)$ & 0.719 & - & \\
\hline Cardiomyopathy ( 1 = yes $)$ & $0.60(0.12-3.00)$ & 0.538 & - & \\
\hline Comorbidities & $0.67(0.42-1.08)$ & 0.097 & $0.58(0.31-1.07)$ & 0.081 \\
\hline \multicolumn{5}{|l|}{ Genetic background } \\
\hline PGRN mutations & $5.11(1.83-14.2)$ & 0.002 & $3.62(1.12-11.7)$ & 0.032 \\
\hline$A P O E \varepsilon 4$ & $1.24(0.54-2.84)$ & 0.615 & $0.95(0.32-2.81)$ & 0.920 \\
\hline MAPT H2 haplotype & $2.67(1.10-6.46)$ & 0.029 & $3.23(1.08-9.69)$ & 0.036 \\
\hline \multicolumn{5}{|l|}{$V E G F$} \\
\hline$-2578 \mathrm{C} / \mathrm{A}, \mathrm{AA}$ & $0.81(0.28-2.36)$ & 0.703 & - & \\
\hline$-1190 \mathrm{G} / \mathrm{A}, \mathrm{AA}$ & $1.17(0.40-3.49)$ & 0.772 & - & \\
\hline$-1154 \mathrm{G} / \mathrm{A}, \mathrm{AA}$ & $0.61(0.15-2.48)$ & 0.491 & - & \\
\hline$-634 \mathrm{G} / \mathrm{C}, \mathrm{CC}$ & $1.33(0.50-3.52)$ & 0.568 & - & \\
\hline VEGF mutations & $0.92(0.59-1.43)$ & 0.699 & $1.24(0.80-1.94)$ & 0.332 \\
\hline
\end{tabular}

bvFTD = Behavioral variant of frontotemporal dementia.

univariate model, and $\mathrm{OR}=3.23,95 \% \mathrm{CI}=1.08-9.69$, $\mathrm{p}=0.036$ for multivariate model) had a 3 -fold increased hazard risk of mortality/early institutionalization compared to the reference ('wild') genotypes. Conversely, $A P O E$ genotype and those VEGF polymorphisms previously associated with increased risk for FTLD [21] were not associated with survival in the FTLD sample.

Figure 1 displays the estimated discrete-time survival probabilities of the multivariate model for the four PGRN $\times M A P T$ groups at the mean value for age at onset $(=64$ years), and at the reference category $(=0)$ for the other covariates.

\section{Discussion}

The evaluation of predictors of survival in FTLD is essential for a number of reasons. First of all, it allows the identification of factors that can be targeted to reduce the mortality risk, and to define faster decliners eligible for therapeutic interventions. This would allow clinicians to

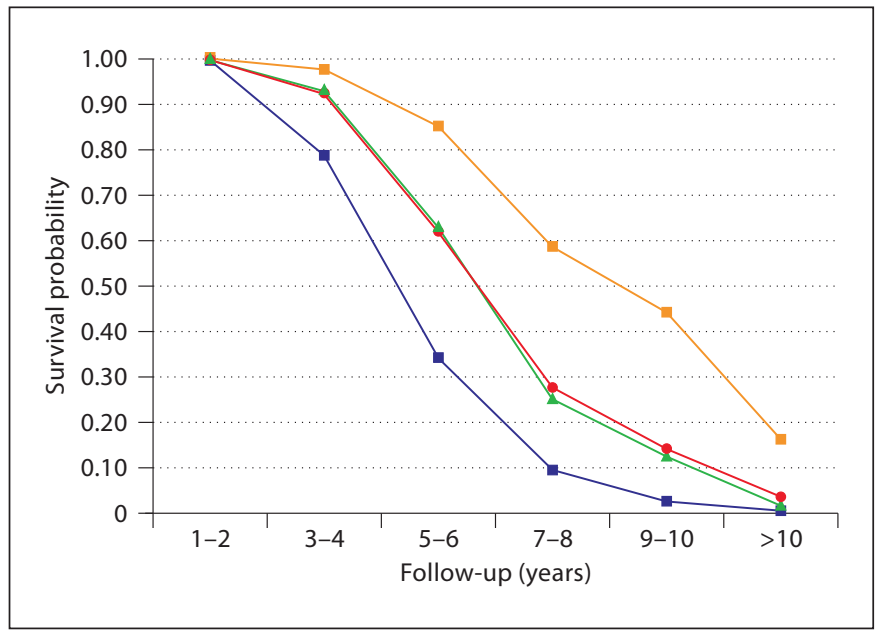

Fig. 1. Estimated discrete-time survival probabilities in patients with different genetic backgrounds. Blue = Patients with PGRN pathogenetic mutations and carrying $M A P T{ }^{*} \mathrm{H} 2$ haplotype; green = patients carrying $M A P T{ }^{*} \mathrm{H} 2$ haplotype without $P G R N$ pathogenetic mutations; red $=$ patients carrying $P G R N$ pathogenetic mutations without $M A P T{ }^{*} \mathrm{H} 2$ haplotype; orange = no atrisk genetic background. 
meet caregivers' and patients' expectations and counsel on disease course and disease progression. Moreover, the estimate of mortality risk might be of help in reducing the number of patients needed in clinical trials, and in establishing the effects of a disease-modifying drug within a reasonable time frame.

Up to now, only a few studies on natural disease course and survival predictors are available. It is well demonstrated that neither demographic characteristics, nor comorbidities, nor family history of dementia can help clinicians to predict the mean survival rate $[5,6,10,26]$. It has previously been suggested that a data-driven approach on neuropsychological data might be of help in identifying patients at higher risk of progression [10]. On the other hand, no data on the role of genetic background in modulating survival rate are available.

In the present work, we suggest that genetic background is not only a significant determinant in monogenic and polygenic FTLD, but that it influences disease course. Both pathogenic PGRN mutations and MAPT ${ }^{*} \mathrm{H} 2$ haplotype were significantly associated with poor prognosis over time.

Only one previous study has reported the effect of $P G R N$ mutations on survival in FTLD patients, arguing that patients bearing $P G R N$ mutations had a shorter survival (5 years) than patients without $P G R N$ mutation-associated disorder [27]. Accordingly, it has been demonstrated that patients carrying PGRN mutations have more generalized atrophy and smaller brains at postmortem compared to patients without $P G R N$ mutations, therefore suggesting that $P G R N$ results in a more rapid, 'malignant' form of FTLD [28].

Beyond the key role of autosomal dominant inherited disorder, our findings also demonstrated a significant association between the presence of ${ }^{*} \mathrm{H} 2$ allele within $M A P T$ gene and worse prognosis. The mechanism by which MAPT gene polymorphisms contribute to the modulation of FTLD in these patients is currently un- clear; it could be related to an effect on tau expression or to an association with other disease-modifying factors. In fact, $\mathrm{H} 1$ and $\mathrm{H} 2$ alleles have different transcriptional activity in human cell lines with $\mathrm{H} 1$ being more efficient at driving MAPT gene expression than $\mathrm{H} 2$ allele [29]. In the same way, functional brain imaging studies have supported the claim of a more severe frontal impairment in ${ }^{*} \mathrm{H} 2$ compared to $\mathrm{H} 1$ carriers in FTLD, thus leading to a faster progression [30, 31].

These findings add to the growing body of literature that argues that the clinical course of FTLD is heterogeneous. The observations of the present study might be of help in clinical practice, but we recognize that they entail some limitations. It is noteworthy that the results of this study need to be replicated in other work, and neuropathological confirmation would be necessary to further confirm the present findings. Furthermore, one of the drawbacks of the present study is that we considered both institutionalization and death as an outcome measure, this being able to influence the final results.

In conclusion, the present work argues that genetic background is not only crucial in disease pathogenesis and disease onset, but it modulates disease course. Establishing disease-modifiable and nonmodifiable factors of poor prognosis is mandatory to define homogeneous patient groups to include in future clinical trials and to monitor efficacy of future interventions. Future studies comparing prognosis in the different autosomal dominant FTLDs would be of interest.

\section{Acknowledgements}

The authors wish to thank the patients and their families for taking part in this study. The authors are indebted to Drs. Chiara Agosti, Antonella Alberici, and Maura Cosseddu for clinical assistance. This study was supported by grants of Ente Universitario Lombardia Orientale (EULO) to A. Padovani.
References janowski JQ, Mann DM, Consortium for Frontotemporal Lobar Degeneration: Neuropathologic diagnostic and nosologic criteria for frontotemporal lobar degeneration: consensus of the Consortium for Frontotemporal Lobar Degeneration. Acta Neuropathol 2007;114:5-22.

2 Cairns NJ, Bigio EH, Mackenzie IR, Neumann M, Lee VM, Hatanpaa KJ, White CL 3rd, Schneider JA, Grinberg LT, Halliday G, Duyckaerts C, Lowe JS, Holm IE, Tolnay M, Okamoto K, Yokoo H, Murayama S, Woulfe J, Munoz DG, Dickson DW, Ince PG, Tro-
3 Kipps CM, Nestor PJ, Dawson CE, Mitchell J, Hodges JR: Measuring progression in frontotemporal dementia: implications for therapeutic interventions. Neurology 2008;70: 2046-2052. 
4 Davies RR, Kipps CM, Mitchell J, Kril JJ, Halliday GM, Hodges JR: Progression in frontotemporal dementia: identifying a benign behavioral variant by magnetic resonance imaging. Arch Neurol 2006;63:16271631.

5 Roberson ED, Hesse JH, Rose KD, Slama H, Johnson JK, Yaffe K, Forman MS, Miller CA, Trojanowski JQ, Kramer JH, Miller BL: Frontotemporal dementia progresses to death faster than Alzheimer disease. Neurology 2005;65:719-725.

6 Hodges JR, Davies R, Xuereb J, Kril J, Halliday G: Survival in frontotemporal dementia. Neurology 2003;61:349-354.

7 Rascovsky K, Salmon DP, Lipton AM, Leverenz JB, DeCarli C, Jagust WJ, Clark CM, Mendez MF, Tang-Wai DF, Graff-Radford NR, Galasko D: Rate of progression differs in frontotemporal dementia and Alzheimer disease. Neurology 2005;65:397403.

8 Xie SX, Forman MS, Farmer J, Moore P, Wang Y, Wang X, Clark CM, Coslett HB, Chatterjee A, Arnold SE, Rosen H, Karlawish JHT, Van Deerlin VM, Lee VM-Y, Trojanowski JQ, Grossman M: Factors associated with survival probability in autopsyproven frontotemporal lobar degeneration. J Neurol Neurosurg Psychiatry 2008;79:126129.

9 Josephs KA, Knopman DS, Whitwell JL, Boave BF, Parisi JE, Petersen RC, Dickson DW: Survival in two variants of tau-negative frontotemporal lobar degeneration: FTLDU versus FTLD-MND. Neurology 2005; 65: 645-647.

10 Borroni B, Grassi M, Agosti C, Premi E, Alberici A, Paghera B, Lucchini S, Luca MD, Perani D, Padovani A: Survival in frontotemporal lobar degeneration and related disorders: latent class predictors and brain functional correlates. Rejuvenation Res 2009;12:33-44.

-11 Borroni B, Grassi M, Agosti C, Premi E, Archetti S, Alberici A, Bellelli G, Caimi L, Di Luca M, Padovani A: Establishing shortterm prognosis in frontotemporal lobar degeneration spectrum: role of genetic background and clinical phenotype. Neurobiol Aging 2010;31:270-279.

$\checkmark 12$ Chiu WZ, Kaat LD, Seelaar H, Rosso SM, Boon AJ, Kamphorst W, van Swieten JC: Survival in progressive supranuclear palsy and frontotemporal dementia. J Neurol Neurosurg Psychiatry 2010;81:441-445.

-13 Mioshi E, Hsieh S, Savage S, Hornberger M, Hodges JR: Clinical staging and disease progression in frontotemporal dementia. Neurology 2010;74:1591-1597.

14 Garcin B, Lillo P, Hornberger M, Piguet O, Dawson K, Nestor PJ, Hodges JR: Determinants of survival in behavioral variant frontotemporal dementia. Neurology 2009;73: 1656-1661.
5 Baker M, Mackenzie IR, Pickering-Brown SM, Gass J, Rademakers R, Lindholm C, Snowden J, Adamson J, Sadovnick AD, Rollinson S, Cannon A, Dwosh E, Neary D, Melquist S, Richardson A, Dickson D, Berger Z, Eriksen J, Robinson T, Zehr C, Dickey CA, Crook R, McGowan E, Mann D, Boeve B, Feldman H, Hutton M: Mutations in progranulin cause tau-negative frontotemporal dementia linked to chromosome 17. Nature 2006;442:916-919.

-16 Cruts M, Gijselinck I, van der Zee J, Engelborghs S, Wils H, Pirici D, Rademakers R, Vandenberghe R, Dermaut B, Martin JJ, van Duijn C, Peeters K, Sciot R, Santens P, De Pooter T, Mattheijssens M, Van den Broeck M, Cuijt I, Vennekens K, De Deyn PP, Kumar-Singh S, Van Broeckhoven C: Null mutations in progranulin cause ubiquitin-positive frontotemporal dementia linked to chromosome 17q21. Nature 2006;442:920924.

17 Spillantini MG, Goedert M: Tau protein pathology in neurodegenerative diseases. Trends Neurosci 1998;21:428-433.

18 Borroni B, Yancopoulou D, Tsutsui M, Padovani A, Sawcer SJ, Hodges JR, Spillantini MG: Association between tau $\mathrm{H} 2$ haplotype and age at onset in frontotemporal dementia. Arch Neurol 2005;62:1419-1422.

-19 Borroni B, Perani D, Archetti S, Agosti C, Paghera B, Bellelli G, Di Luca M, Padovani A: Functional correlates of apolipoprotein E genotype in frontotemporal lobar degeneration. BMC Neurol 2006;6:31.

-20 Srinivasan R, Davidson Y, Gibbons L, Payton A, Richardson AM, Varma A, Julien C, Stopford C, Thompson J, Horan MA, Pendleton N, Pickering-Brown SM, Neary D, Snowden JS, Mann DM: The apolipoprotein E epsilon4 allele selectively increases the risk of frontotemporal lobar degeneration in males. J Neurol Neurosurg Psychiatry 2006;77:154-158.

- 21 Borroni B, Ghezzi S, Agosti C, Archetti S, Fenoglio C, Galimberti D, Scarpini E, Di Luca M, Bresolin N, Comi GP, Padovani A, Del Bo R: Preliminary evidence that VEGF genetic variability confers susceptibility to frontotemporal lobar degeneration. Rejuvenation Res 2008;11:773-780.

22 McKhann GM, Albert MS, Grossman M, Miller B, Dickson D, Trojanowski JQ, Work Group on Frontotemporal Dementia and Pick's Disease: Clinical and pathological diagnosis of frontotemporal dementia: report of the Work Group on Frontotemporal Dementia and Pick's Disease. Arch Neurol 2001;58:1803-1809.
23 Neary D, Snowden J, Gustafson L, Passant U, Stuss D, Black S, Freedman M, Kertesz A, Robert P, Albert M, Boone K, Miller B, Cummings J, Benson D: Frontotemporal lobar degeneration: a consensus on clinical diagnostic criteria. Neurology 1998;51:1546-1554.

24 Borroni B, Archetti S, Alberici A, Agosti C, Gennarelli M, Bigni B, Bonvicini C, Ferrari M, Bellelli G, Galimberti D, Scarpini E, Di Lorenzo D, Caimi L, Caltagirone C, Di Luca M, Padovani A: Progranulin genetic variations in frontotemporal lobar degeneration: evidence for low mutation frequency in an Italian clinical series. Neurogenetics 2008;9: 197-205.

25 Singer JD, Willett JB: It's about time: using discrete-time survival analysis to study duration and the timing of events. J Educ Stat 1993;18:155-195.

-26 Hu WT, Seelaar H, Josephs KA, Knopman DS, Boeve BF, Sorenson EJ, McCluskey L, Elman L, Schelhaas HJ, Parisi JE, Kuesters B, Lee VM, Trojanowski JQ, Petersen RC, van Swieten JC, Grossman M: Survival profiles of patients with frontotemporal dementia and motor neuron disease. Arch Neurol 2009;66:1359-1364.

27 Beck J, Rohrer JD, Campbell T, Isaacs A, Morrison KE, Goodall EF, Warrington EK, Stevens J, Revesz T, Holton J, Al-Sarraj S, King A, Scahill R, Warren JD, Fox NC, Rossor MN, Collinge J, Mead S: A distinct clinical, neuropsychological and radiological phenotype is associated with progranulin gene mutations in a large UK series. Brain 2008;131(Pt 3):706-720.

28 Josephs KA, Ahmed Z, Katsuse O, Parisi JF, Boeve BF, Knopman DS, Petersen RC, Davies P, Duara R, Graff-Radford NR, Uitti RJ, Rademakers R, Adamson J, Baker M, Hutton ML, Dickson DW: Neuropathologic features of frontotemporal lobar degeneration with ubiquitin-positive inclusions with progranulin gene (PGRN) mutations. J Neuropathol Exp Neurol 2007;66:142-151.

29 Kwok JB, Teber ET, Loy C, Hallupp M, Nicholson G, Mellick GD, Buchanan DD, Silburn PA, Schofield PR: Tau haplotypes regulate transcription and are associated with Parkinson's disease. Ann Neurol 2004;55:329334.

30 Laws SM, Perneczky R, Drzezga A, DiehlSchmid J, Ibach B, Bäuml J, Eisele T, Förstl H, Kurz A, Riemenschneider M: Association of the tau haplotype $\mathrm{H} 2$ with age at onset and functional alterations of glucose utilization in frontotemporal dementia. Am J Psychiatry 2007;164:1577-1584.

- 31 Borroni B, Perani D, Agosti C, Anchisi D, Paghera B, Archetti S, Alberici A, Di Luca M, Padovani A: Tau haplotype influences cerebral perfusion pattern in frontotemporal lobar degeneration and related disorders. Acta Neurol Scand 2008;117:359-366. 